\title{
Ebbinghaus Revisited: Influences of the BDNF Val66Met Polymorphism on Backward Serial Recall Are Modulated by Human Aging
}

\author{
Shu-Chen Li $^{1,2 *}$, Christian Chicherio ${ }^{1,3 *}$, Lars Nyberg ${ }^{4}$, \\ Timo von Oertzen ${ }^{1}$, Irene E. Nagel ${ }^{1,2}$, Goran Papenberg ${ }^{1}$, \\ Thomas Sander $^{5}$, Hauke R. Heekeren ${ }^{1,2,6,7}$, Ulman Lindenberger ${ }^{1,2}$, \\ and Lars Bäckman ${ }^{1,2,8}$
}

\begin{abstract}
The brain-derived neurotrophic factor (BDNF) plays an important role in activity-dependent synaptic plasticity, which underlies learning and memory. In a sample of 948 younger and older adults, we investigated whether a common Val66Met missense polymorphism (rs6265) in the BDNF gene affects the serial position curve- a fundamental phenomenon of associative memory identified by Hermann Ebbinghaus more than a century ago. We found a BDNF polymorphism effect for backward recall in older adults only, with Met-allele carriers (i.e., individuals with reduced BDNF signaling) recalling fewer items than Val homozygotes. This
\end{abstract}

\section{INTRODUCTION}

The common task of remembering a series of events in sequential order relies on both associative and working memory processes (Botvinick \& Watanabe, 2007; Richardson, 2007; Marshuetz, 2005; Sun et al., 2005; Talmi, Grady, Goshen-Gottstein, \& Moscovitch, 2005). Since the days of Ebbinghaus, memory for order has been captured by the serial position curve, which depicts the robust finding that recall accuracy is related to the positions of memory items in a sequence: Items presented at the beginning and the end of a sequence are typically recalled better than items in the middle (e.g., Murdock, 1962; Kirkpatrick, 1894; Ebbinghaus, 1885). The recall advantage of early and late items of a sequence is known as primacy and recency effects, respectively. Serial position and recall direction affect the associative strength between items, as well as the susceptibility to interference from other items

\footnotetext{
${ }^{1}$ Max Planck Institute for Human Development, Berlin, Germany, ${ }^{2}$ Berlin Neuroimaging Center, Berlin, Germany, ${ }^{3}$ University of Geneva, Geneva, Switzerland, ${ }^{4}$ Umeå University, Umeå, Sweden, ${ }^{5}$ Cologne Center for Genomics, Cologne, Germany, ${ }^{6}$ Charité University Medicine, Berlin, Germany, ${ }^{7}$ Max Planck Institute for Cognitive and Brain Sciences, Leipzig, Germany, ${ }^{8}$ Karolinska Institute, Stockholm, Sweden

*These authors contributed equally to the article.
}

effect was specific to the primacy and middle portions of the serial position curve, where intralist interference and associative demands are especially high. The poorer performance of older Met-allele carriers reflected transposition errors, whereas no genetic effect was found for omissions. These findings indicate that effects of the BDNF polymorphism on episodic memory are most likely to be observed when the associative and executive demands are high. Furthermore, the findings are in line with the hypothesis that the magnitude of genetic effects on cognition is greater when brain resources are reduced, as is the case in old age.

during encoding and retrieval. Items at earlier input and output positions (e.g., items at the primacy portion in forward recall, which are serially recalled from the beginning to the end of the list; and items at the recency portion in backward recall, which are serially recalled from the end to the beginning of the list) are thought to have greater interitem associative strength, and to be less susceptible to intralist and output interference (for reviews, see Botvinick \& Plaut, 2006; Lewandowsky \& Murdock, 1989). Furthermore, evidence suggests that backward recall involves more complex retrieval operations than forward recall (e.g., Thomas, Milner, \& Haberlandt, 2003; Li \& Lewandowsky, 1993, 1995; see Richardson, 2007 for a review).

The advent of molecular genetics has opened up possibilities for casting new light on long-standing issues in the experimental psychology of human memory. Genebehavior association studies (see McClearn, 2006, for a review) and genomic imaging research (see Green et al., 2008; Meyer-Lindenberg \& Weinberger, 2006, for reviews) have provided novel insights into individual differences in memory and cognition as well as associated brain mechanisms. Here, we focus on the gene coding for the brainderived neurotrophic factor (BDNF). BDNF regulates the production of a variety of cortical neurons and mediates developmental phenomena such as neuronal proliferation, differentiation, and survival in developing as well as 
adult nervous systems (see Reichardt, 2006, for a review). $\mathrm{BDNF}$ also regulates activity-dependent changes in synaptic plasticity, such as long-term potentiation in the hippocampus, which are fundamental to memory formation (e.g., Kuczewski, Porcher, Lessmann, Medina, \& Gaiarsa, 2009; Berkinschtein et al., 2008). Consistent with these assertions, pharmacological and genetic deprivation of BDNF in animals induce deficits in hippocampal-dependent spatial memory and other forms of associative learning (e.g., Hall, Thomas, \& Everitt, 2000; Saarelainen et al., 2000; Linnarsson, Bjorklund, \& Ernfors, 1997).

In humans, a common functional polymorphism of the BDNF gene produces a valine to methionine (Val66Met) amino acid substitution, which affects enzymatic activity such that secretion of BDNF in neurons is lower in individuals carrying the Met allele than in Val homozygotes (Egan et al., 2003). Initial work with younger adults associated the BDNF Met allele with poorer performance in episodic memory tasks, such as prose recall (Egan et al. 2003) and scene recognition (Hariri et al., 2003), as well as reduced hippocampal and frontal volumes (Pezawas et al., 2004) and reduced BOLD signal during episodic encoding and retrieval (Hariri et al., 2003). Such a Met disadvantage in episodic memory has been documented in several follow-up studies (e.g., Goldberg et al., 2008; Ho et al., 2006; Dempster et al., 2005). In the seminal paper by Egan et al. (2003), however, no BDNF gene-related differences were observed in the California Verbal Learning Test, a standard instrument for assessing episodic memory. Other studies have also failed to replicate a BDNF Met allelle disadvantage for a variety of verbal and nonverbal memory tasks in younger individuals (e.g., Hashimoto et al., 2008; Hansell et al., 2007; Strauss et al., 2004), or found weak and inconsistent support for genotype differences (Echeverria et al., 2005). The inconsistencies in existing findings may, in part, be due to differences in sample characteristics across studies. For instance, two recent studies with participants sampled from the entire adult life span showed that indicators of vascular risk (e.g., hypertension, high blood glucose levels) interacted with BDNF gene status in affecting episodic memory (Raz, Rodrigue, Kennedy, \& Land, 2009; Raz et al., 2008).

Age of the participant is another factor that may affect the magnitude of the observed genetic effects (e.g., Nagel et al., 2008). Aging is associated with reduced brain resources at multiple levels, including changes in gray and white matter integrity as well as losses in neuromodulatory functions (see Bäckman, Nyberg, Lindenberger, Li, \& Farde, 2006; Cabeza, Nyberg, \& Park, 2005; Raz et al., 2005; Li, Lindenberger \& Sikström, 2001 for reviews). Of particular relevance to the current research, both animal and human evidence shows that activity-dependent up-regulation of $\mathrm{BDNF}$ and the level of its receptor tyrosine kinase B (trkB) are compromised in old age (Webster, Herman, Kleinman, \& Shannon Weickert, 2006; Adlard, Perreau, \& Cotman, 2005; Monti, Berteotti, \& Contestabile, 2005; see TapiaArancibia, Rage, Givalois, \& Arancibia, 2004, for a review).
Lindenberger et al. (2008) hypothesized that age-related losses in structural and neurochemical brain resources may modulate the extent to which common genetic variations affect cognitive functioning. This hypothesis rests on the assumption that the function relating brain resources to cognition is nonlinear, so that genetic variability is more likely to result in performance differences when resources move away from close-to-optimal levels, as is the case in aging. Initial support for this view was reported by Nagel et al. (2008), who found that the effects of the BDNF gene on executive functioning and working memory were magnified in old age and modulated by the catechol-O-methyltransferase (COMT) genotype. Further, Miyajima, Ollier, et al. (2008) and Miyajima, Quinn, et al. (2008) reported a clear cognitive advantage of homozygotic BDNF Val carriers over Met carriers in a sample of older adults, and Nemoto et al. (2006) found that older BDNF Met carriers showed greater volume reductions in dorsolateral prefrontal cortex than Val homozygotes. A link between serum BDNF levels and memory performance has also been demonstrated in older adults (Komulainen et al., 2008).

In this study, we used the classical serial-recall paradigm to clarify the role of the BDNF gene in episodic memory. Younger and older Val and Met carriers of the BDNF gene were assessed on forward and backward serial recall of verbal information. The study had three empirically substantiated points of departure. First, the nonrecency portions of the serial position curve rely more on associative binding and executive mechanisms than the recency portion (e.g., Botvinick \& Plaut, 2006). Second, backward recall involves more complex operations than forward recall (see Richardson, 2007 for a review), as it requires reinvoking both visuospatial and audioverbal representations of the item sequences; whereas forward recall relies mainly on audioverbal representations (Li \& Lewandowsky, 1995). Relatedly, it has also been suggested that backward recall entails a more time-consuming multiple-scanning retrieval strategy (Thomas et al., 2003; Murdock, 1995; Conrad, 1965). Third, activity-dependent up-regulation of BDNF is reduced in aging (e.g., Webster et al., 2006). Thus, we made three predictions: (a) the effect of the BDNF polymorphism is most pronounced for nonrecency portions of the serial position curve, where the associative binding and executive demands are higher; (b) given more complex retrieval operations, backward recall is more sensitive to allelic differences in the BDNF polymorphism than forward recall; and (c) provided that BDNF secretion is down-regulated in old age and that older Met carriers show exacerbated brain-volume losses, individual differences in the BDNF polymorphism have a greater effect on episodic memory performance in older compared to younger adults.

\section{METHODS \\ Participants}

Nine hundred forty-eight healthy volunteers from two age groups were examined: 382 younger adults (mean age $=$ 
25.6 years, $S D=3.0$, range $=20-31 ; 166$ women and 216 men) and 566 older adults (mean age $=65.0$ years, $S D=2.8$, range $=60-71 ; 301$ women and 265 men). About 30\% $(n=298)$ of the participants in the current sample were included in an earlier study on aging and genetic effects in working memory (Nagel et al., 2008). Participants were recruited in Berlin, Germany, via newspaper announcements, posters in public transportation, and postcards in restaurants and pubs. All participants were white, right-hand dominant, and had normal or correctedto-normal vision. None reported a history of medical, neurological, psychiatric disease, head injuries, and none were on medications that may affect memory function. No participant had symptoms of dementia (all scored over 27 on the Mini-Mental Status Examination). Given that the effect of the BDNF polymorphism on memory may be influenced by vascular health (Raz et al., 2008, 2009), we assessed a range of relevant indicators, including diagnoses of cardiovascular disease, diabetes, and arterial hypertension. Importantly, the BDNF genotype groups did not dif- fer statistically with respect to these markers of vascular health, or on a derived measure of hypertension grade (see Table 1 for details) computed according to the guidelines published by the World Health Organization (WHO) and the International Society of Hypertension (ISH; WHO, ISH Writing Group, 2003). Participants gave informed consent and were paid $€ 7$ per hour for their participation. The ethics committee of the Charite Universitätsmedizin Berlin approved the study.

\section{Genotyping}

DNA was extracted from peripheral blood using standard methods. The nonsynonymous BDNF (Val66Met) singlenucleotide polymorphism (dbSNP: rs6265; c.196G >A, p.Val66Met) was genotyped in a 384-well microtiter plate format using the TaqMan $5^{\prime}$-exonuclease assay as described elsewhere (Lang, Hellweg, et al., 2007; Lang, Sander, et al., 2007; Meyer-Lindenberg \& Weinberger, 2006; Egan et al., 2003; Hariri et al., 2003). The sequences of primers and

Table 1. Demographic Characteristics, Indicators of Vascular Health, and BDNF Genotype in Younger and Older Adults

\begin{tabular}{|c|c|c|c|c|}
\hline & \multicolumn{4}{|c|}{ BDNF Genotype } \\
\hline & \multicolumn{2}{|c|}{ Younger } & \multicolumn{2}{|c|}{ Older } \\
\hline & $\begin{array}{c}\text { Met-allele Carriers } \\
(n=136)\end{array}$ & $\begin{array}{l}\text { Val Homozygotes } \\
\quad(n=246)\end{array}$ & $\begin{array}{l}\text { Met-allele Carriers } \\
(n=194)\end{array}$ & $\begin{array}{c}\text { Val Homozygotes } \\
\quad(n=372)\end{array}$ \\
\hline \multicolumn{5}{|l|}{ Demographics } \\
\hline Age range & $20-30$ & $20-31$ & $60-70$ & $60-71$ \\
\hline Age $(M \pm S D)$ & $25.4(3.0)$ & $25.7(3.0)^{\mathrm{a}}$ & $64.8(2.8)$ & $65.2(2.8)^{\mathrm{a}}$ \\
\hline Female/Male & $59 / 77$ & $107 / 139^{\mathrm{b}}$ & $97 / 97$ & $204 / 168^{b}$ \\
\hline$\%$ Female & 43 & 44 & 50 & 55 \\
\hline Years of education $(M \pm S D)$ & $12.5(1.3)$ & $12.7(1.2)^{\mathrm{a}}$ & $10.7(1.8)$ & $10.9(1.7)^{\mathrm{a}}$ \\
\hline State of health $(M \pm S D)$ & $4.1(0.6)$ & $4.2(0.6)^{\mathrm{a}}$ & $3.9(0.7)$ & $3.9(0.6)^{\mathrm{a}}$ \\
\hline \multicolumn{5}{|l|}{ Indicators of Vascular Health } \\
\hline Diabetes & $0 \%$ & $0 \%$ & $6.7 \%$ & $5.9 \%$ \\
\hline Cardiovascular disease & $3.7 \%$ & $2.5 \%$ & $33.5 \%$ & $36.7 \%^{\mathrm{b}}$ \\
\hline Hypertension medication & $1.5 \%$ & $0 \%$ & $29.9 \%$ & $33.2 \%$ \\
\hline Hypertension grade $(M \pm S D)$ & $0.65(0.77)$ & $0.57(0.68)^{\mathrm{a}}$ & $1.55(0.99)$ & $1.52(0.97)^{\mathrm{a}}$ \\
\hline Percentage of hypertensives & $49.3 \%$ & $47.1 \%{ }^{b}$ & $87.6 \%$ & $87.6 \%{ }^{\mathrm{b}}$ \\
\hline
\end{tabular}

$M=$ mean; $S D=$ standard deviation; state of health = mean score on a self-rating scale with four questions on 5 -point subscales $(1=$ poor; $5=$ excellent); hypertension grades were computed based on systolic blood pressure (SBP) and diastolic blood pressure (DBP), using the 2003 World Health Organization guidelines; Grade 1: SBP $=140-159$ or DBP $=90-99$; Grade 2: SBP 160-179 or DBP 100-109; and Grade 3: SBP $\geq 180$ or DBP $\geq$ 110, with Grade 1 indicating mild hypertension. The prevalence rates for hypertension are relatively high because of the adoption of the newer 140/ $90 \mathrm{mmHg}$ cutoff in comparison to the 160/95 mmHg cutoff suggested by the old guidelines from 1984. The percentage of hypertensive individuals in our sample reflects the national survey statistics. In a national survey study involving six European countries, Canada, and America, the average prevalence rate of hypertension in adult populations (18-79 years) was highest in Germany (55\%; Wolf-Maier et al., 2003). For analytical purposes, normotensives were assigned a grade of zero. In line with Raz et al. (2009), participants with either of the three hypertensive grades and/or taking hypertension medication were categorized as hypertensives.

${ }^{\mathrm{a}}$ One-way analyses of variance $=n s$.

${ }^{\mathrm{b}} \chi^{2}(1)=n s$. 
TaqMan probes for the SNP genotyping were designed and synthesized by Applied Biosystems (Foster City, CA). The call rate in more than 2500 individuals, including individuals of the current sample, was greater than $99 \%$. Furthermore, the genotyping reliability of the TaqMan assay was examined by genotyping of 186 duplicated DNA samples, which are not part of the present study. All duplicated samples displayed the same genotype as its reference sample. The frequencies of the three BNDF rs6265 genotypes were $64.4 \%(n=246)$ for $\mathrm{Val} / \mathrm{Val}, 33.3 \%(n=127)$ for Val/Met, and 2.3\% $(n=9)$ for Met/Met in the younger group. The corresponding distribution was $65.7 \%(n=$ 372) for Val/Val, 32.2\% $(n=182)$ for Val/Met, and $2.1 \%$ $(n=12)$ for Met/Met in the older group. The genotypic distributions did not deviate significantly from those expected according to Hardy-Weinberg equilibrium (HWE) in either age group [younger, $\chi^{2}(1)=2.51, p=.11$; older, $\left.\chi^{2}(1)=3.63, p=.06\right]$. The lower, albeit nonsignificant, $p$ value in the older group reflects the slightly lower frequency of the Met homozygotes in this group (i.e., 12 vs. 18 as expected by HWE.) Importantly, however, the observed frequencies did not differ between the two age groups $\left[\chi^{2}(2)=0.20, p=.90\right]$.

A recent population study of BDNF gene variations revealed considerable differences in the frequency of the Met allele across 58 global populations (Petryshen et al., 2009). Specifically, the Met66 frequency was $0.55 \%$, $19.9 \%$, and $43.6 \%$ in individuals from Sub-Saharan Africa, Europe, and Asia, respectively. In this context, it should be underscored that the distributions observed in our sample are very similar to other white samples (cf. the $65.6 \%, 31.0 \%$, and $3.4 \%$ distribution for $\mathrm{Val} / \mathrm{Val}$, Val/Met, and Met/Met, observed by Lang, Hellweg, et al., 2007; Lang, Sander, et al., 2007; the 60\%, 34\%, and 6\% distribution for Val/Val, Val/Met, and Met/Met observed by Raz et al., 2008; see also Vepsäläinen et al., 2005). Due to the rarity of Met homozygotes, participants were subdivided into two commonly defined subgroups according to their BDNF Val66Met genotype status: Val/Val and Met-allele carriers.

\section{Experimental Task}

Participants underwent two sessions of cognitive testing. The sessions were held in groups of five to six individuals. Cognitive tasks were administered to investigate processing speed and robustness, executive functioning and working memory, and episodic memory. Here, we focus on the association between the BDNF polymorphism and serial-order memory.

In the serial-recall task, participants were presented with six different lists containing 12 words each. Following presentation of the last item in each list, they were asked to recall each word at its correct position. Word Lists 1 to 3 were recalled in forward order, whereas Word Lists 4 to 6 were recalled in backward order. Items were German nouns with word length varying from four to nine letters. Words that shared two or more initial letters did not appear in the same list. During encoding, participants listened to the words at a rate of $2 \mathrm{sec} /$ word via headphones, while simultaneously viewing a number corresponding to their serial position on a computer screen. At recall, participants used a keyboard to type the first three letters of a word in a response box appearing on the computer screen, on top of which the item position (either 1 to 12 for forward recall or 12 to 1 for backward recall) was indicated. Recall was self-paced. This procedure minimizes potential age differences in typing errors and reaction times (cf. Brehmer, Li, Müller, von Oertzen, \& Lindenberger, 2007). If participants were unable to recall a word, they could skip that position and move on to the next. After completing a list, participants received feedback concerning the percentage of correctly remembered words. The entire task took approximately $35 \mathrm{~min}$ to complete.

For each list, responses were scored using a strict serialrecall criterion: An accurate response required that both the identity of a word and its serial position were correct. Errors were categorized as transpositions (words correctly recalled but in the wrong positions), omissions (words not recalled), commissions (recall of nonstudied words), intrusions (recall of studied words from previous lists), and repetitions. Here, we focus only on transposition errors and omissions because the prevalence rates for the other error types were very low.

\section{Statistical Analysis}

Demographic data were analyzed using analyses of variance (ANOVAs) or $\chi^{2}$ tests, with SPSS for Windows 15.0 (SPSS, Chicago, IL). Behavioral data were analyzed with mixed effect models with maximum likelihood estimation ("Proc Mixed" procedure), using SAS 9.1 for Windows (SAS Institute, Cary, NC). In contrast to standard ANOVA, mixed effect models allow for differences in variances and covariances between age groups and BDNF allelic variants, which is more suitable here given the multivariate heterogeneity of variances and covariances in our data, as reflected in the Box's $M$ tests for forward $(p<.001)$ and backward $(p<.001)$ recall. Given the female superiority in episodic memory (e.g., Herlitz \& Rehnman, 2008), sex was used as a covariate in the statistical analyses. Furthermore, COMT genotype was also used as a covariate, as previous research shows that COMT affects memory and may interact with BDNF (e.g., Nagel et al., 2008; see Savitz, Solms, \& Ramesar, 2006 for a review). All effects reported here are also statistically reliable when COMT is not entered as a covariate.

\section{RESULTS}

For each recall direction, serial position effects were analyzed with respect to three portions of the curve by subdividing 
the 12 positions into primacy (Positions 1 to 4 ), middle (Positions 5 to 8), and recency (Positions 9 to 12) portions. The analysis for forward recall (Age $\times$ BDNF polymorphism $\times$ Portion) revealed significant main effects of age $[F(1,504)=544.0, p<.001]$, portion $[F(2,588)=$ 991.6, $p<.001]$, and a reliable interaction between age and portion $[F(2,588)=29.4, p<.001]$. As can be seen in Figure 1A, older adults performed less accurately overall, and this difference was more pronounced for the middle and recency portions of the serial position curve, particularly the middle portion. However, the main effect of BDNF and the interactions involving this factor fell far short of significance ( $p s>$.10). Furthermore, as hypertension may affect memory and interact with individual differences in genotype, analyses with hypertension (normotensive vs. hypertensive) as an additional betweenperson factor were conducted. Using similar criteria as used in earlier studies (e.g., Raz et al., 2009), individuals who had a diagnosis of hypertension and/or were taking antihypertensive medication, or had blood pressure that exceeded WHO's $140 \mathrm{mmHg} / 90 \mathrm{mmHg}$ criteria for hypertension, were classified as hypertensive. The main effect of hypertension was not significant ( $p=.57)$, and hyper- tension did not interact with age $(p=.49)$, portion $(p=$ $.97)$, or BDNF status ( $p=.31)$. Similarly, other higherorder interactions involving hypertension also were not significant.

For backward recall, the same type of analysis again yielded significant main effects of age $[F(1,476)=418.0$, $p<.001]$, portion $[F(2,667)=552.1, p<.001]$, and a significant interaction between age and portion $[F(2,667)=$ 123.2, $p<.001]$. These results indicate that older people generally performed less well, and that the age difference was most pronounced for the primacy and middle portions of the curve. Of chief interest was the fact that the Age $\times$ BDNF interaction $[F(1,474)=4.4, p<.05]$ and the triple interaction among age, BDNF, and portion $[F(2,667)=$ $3.4, p<.05$ ] were statistically reliable. Planned comparisons showed that older Met-allele carriers recalled fewer items than older Val homozygotes in both the primacy and middle portions $[t(410)=3.09, p<.01$, and $t(466)=$ $3.15, p<.01$, respectively], but not in the recency portion $[t(378)=-1.32, p=.19]$ (see Figure 1B). An analysis with hypertension as an additional factor was conducted here, too. Similar to the results found for forward recall, neither the main effect of hypertension nor any of the interactions
Figure 1. Proportion of words recalled in correct serial position as a function of age, BDNF genotype, and portion of the curve in forward (A) and backward (B) recall. Error bars represent standard errors around the means.

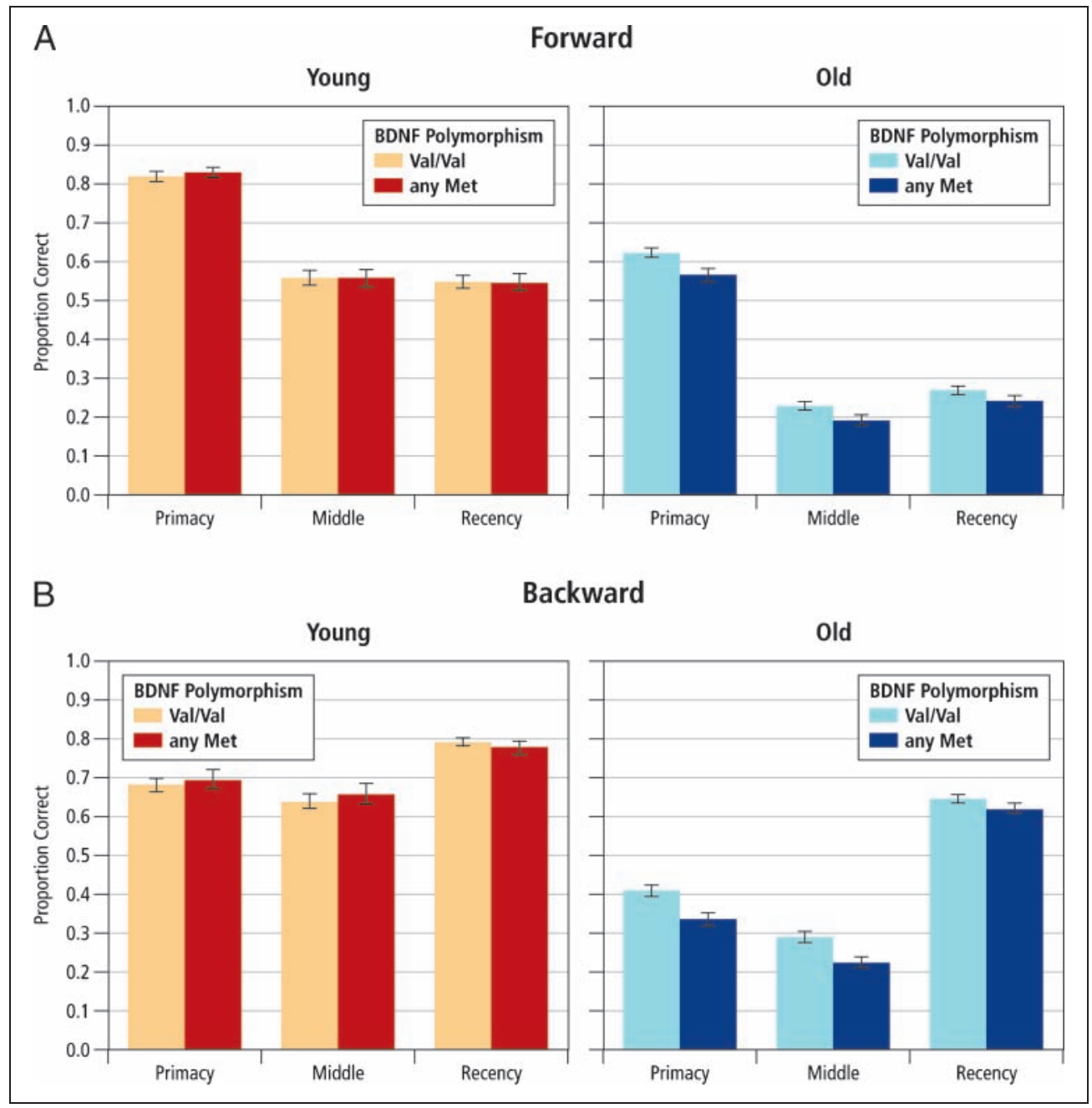




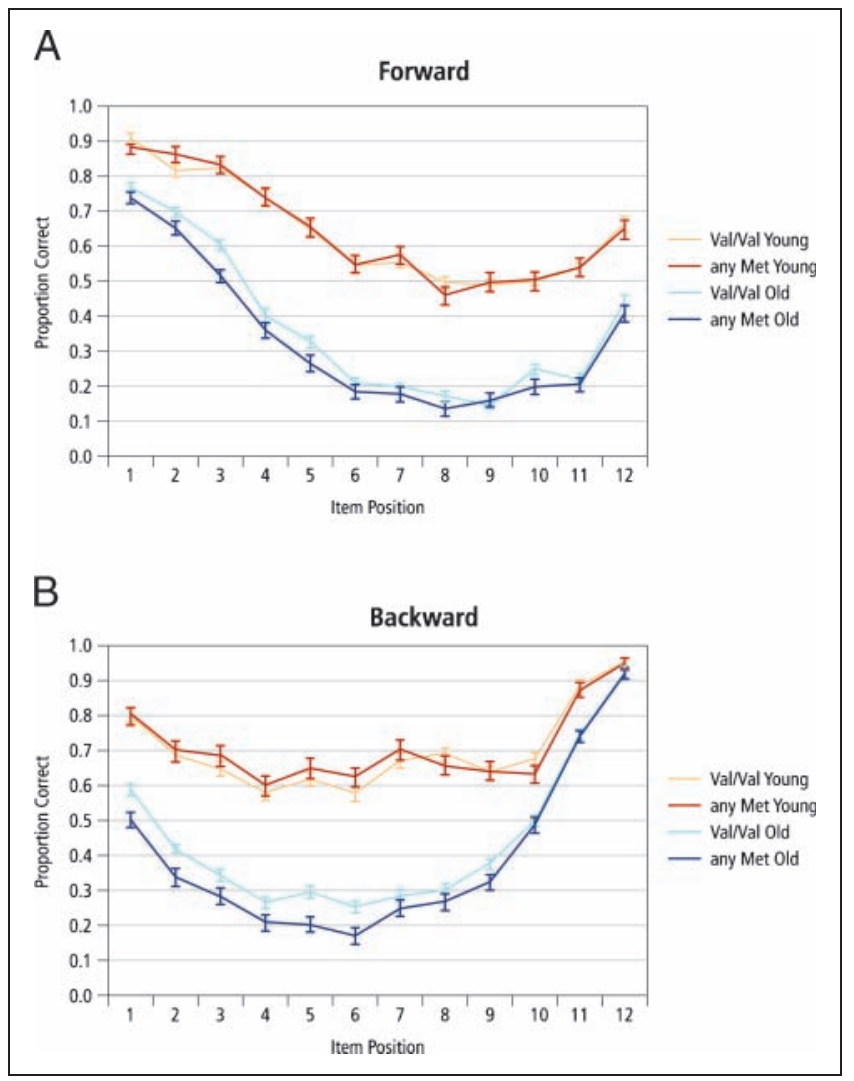

Figure 2. Serial position curves as a function of age and BDNF genotype in forward (A) and backward (B) recall. Error bars represent standard errors around the means.

involving hypertension were significant ( $p$ values ranged from .13 to .81 ) in backward recall. For both forward and backward recall, analyses across all 12 serial positions yielded the same pattern of nonsignificant results and significant effects, respectively. These data are presented in Figure 2A and B.

To examine which error type was reflected in older Met carriers' backward recall deficit, we analyzed omissions and transposition errors. For these analyses, we focused on the specific portions of backward recall where the Age $\times$ BDNF interaction was reliable, and thus, aggregated performance across the primacy and middle segments of the curve. With respect to omissions, there was a significant main effect of age $[F(1,674)=421.2$, $p<.001$ ], with older adults producing more such errors than younger adults. BDNF genotype status did not affect the number of omissions. For transposition errors, we also found a significant main effect of age $[F(1,518)=$ $16.0, p<.001]$. However, here the interaction between age and BDNF was reliable $[F(1,515)=3.7, p<.05]$. Follow-up tests indicated that older Met-allele carriers produced more transposition errors than older Val homozygotes $[t(301)=3.04, p<.001]$, whereas this was not true for younger adults $[t(258)=0.03$, ns; see Table 2]. Additional analyses adding hypertension as a factor only yielded a significant Age $\times$ Hypertension interaction for transposition errors $[F(1,549)=5.10, p<.05]$. However, this interaction should be interpreted cautiously. This is so because it reflected the fact that younger hypertensives made fewer errors than younger normotensives, whereas older normotensives made fewer errors than their hypertensive counterparts.

\section{DISCUSSION}

This research revisited a classic phenomenon in the experimental psychology of memory, the serial position curve in episodic recall (e.g., Kirkpatrick, 1894; Ebbinghaus, 1885), from a genomic perspective. Our data show that the influence of the BDNF Val66Met polymorphism on episodic memory performance was magnified in old age. Whereas younger $\mathrm{Val} / \mathrm{Val}$ and Met-allele carriers of the BDNF gene exhibited similar levels of serial recall, older homozygotic Val carriers outperformed older Met-allele carriers. However, the advantage of Val homozygotes in the older sample was qualified by both recall direction and serial position: There were no genotype differences in forward recall or for the recency position of the serial position curve; the $\mathrm{Val} / \mathrm{Val}$ advantage was confined to the primacy and middle portions of the curve in backward recall.

Evidence for the effects of the BDNF polymorphism on memory is mixed in younger adults, with some studies showing a Val advantage (e.g., Goldberg et al., 2008; Ho et al., 2006; Dempster et al., 2005; Egan et al., 2003) and

Table 2. Mean Number of Transposition and Omission Errors per List across the Primacy and Middle Portions of the Backward Serial Recall Curve as a Function of Age and BDNF Genotype

\begin{tabular}{|c|c|c|c|c|}
\hline & \multicolumn{4}{|c|}{ BDNF Genotype } \\
\hline & \multicolumn{2}{|c|}{ Younger } & \multicolumn{2}{|c|}{ Older } \\
\hline & Met-allele Carriers & Val Homozygote & Met-allele Carriers & Val Homozygote \\
\hline \multicolumn{5}{|l|}{ Type of Errors } \\
\hline Transpositions $(M \pm S D)$ & $1.03(1.26)$ & $1.03(1-15)$ & $1.52(1.28)$ & $1.20(0.93)$ \\
\hline Omissions $(M \pm S D)$ & $0.98(1.41)$ & $1.15(1.37)$ & 3.34 (1.98) & $3.45(1.91)$ \\
\hline
\end{tabular}

$M=$ mean; $S D=$ standard deviation $( \pm 1)$; maximum number of errors per word list summed across the primacy and middle portions of the curve is 8 . 
others not (Hashimoto et al., 2008; Hansell et al., 2007; Echeverria et al., 2005; Strauss et al., 2004). Two recent studies demonstrated a clear cognitive advantage of Val carriers in samples of older adults (Miyajima, Ollier, et al., 2008; Miyajima, Quinn, et al., 2008). However, another recent report involving persons at 70 years of age failed to find any BDNF genotype differences using a large battery of cognitive tests including measures of episodic memory (Houlihan et al., 2009). Results from our study shed new light on these discrepancies. First, as is evident in the current data and those of Nagel et al. (2008), chronological age, which can be seen as a proxy of individual differences in brain resources (Lindenberger et al., 2008), modulated genetic effects: In older adults whose cognitive functions are subserved by suboptimal levels of brain resources, genetic effects are more apparent. Second, our findings also highlight that characteristics of episodic memory tasks, such as the relative demands of associative binding and the complexity of retrieval operations, also appear to affect the magnitude of the observed genetic effects. Specifically, the absence of BDNF gene effects for pre-recency items in backward recall provides clues for interpreting the nature of the mixed evidence in earlier studies. Our data suggest that the Val advantage in episodic memory is most easily disclosed under task conditions that pose high demands on both associative binding and executively taxing retrieval operations. In backward recall, items in the initial and middle portion of the serial position curve are recalled later, have weaker interitem and item-position associations, and are more prone to output interference (e.g., Botvinick \& Plaut, 2006); thus, the demands on associative binding are especially high for these items. Indeed, brain imaging research shows greater activity in the hippocampus and ventral and dorsolateral prefrontal cortex during recognition of pre-recency compared with recency items (Talmi et al., 2005).

Further, although items in backward serial recall may also rely on verbal representations as those in forward recall, backward recall requires more complex retrieval operations (e.g., Thomas et al., 2003; Li \& Lewandowsky, 1993, 1995). Whereas forward recall relies on phonological representations of order information (e.g., Healy, 1975), backward recall relies additionally on visuospatial representations (e.g., O'Connor \& Hermelin, 1976; Conrad, 1972). This is evidenced by data showing that backward, but not forward, recall is sensitive to visuospatial interference (Li \& Lewandowsky, 1993, 1995). Imaging data lend further support to this notion. Specifically, backward digit recall activates left prefrontal, parietal and occipital areas in addition to right prefrontal areas, which are also activated during forward recall (Sun et al., 2005; Hoshi et al., 2000); greater activity in the occipital and parietal cortices during backward recall suggests that visuospatial retrieval processes are involved. Moreover, the response time data indicated that backward recall took longer than forward recall. This result indicates that backward recall relies on more complex retrieval operations that may involve scanning items in forward order first and then recalling these items in backward order (Thomas et al., 2003).

The BDNF gene effects observed in this study were confined to pre-recency items in backward recall. The combination of having to recall items in backward order with a long lag between study and test maximizes the demands on strategic retrieval operations. The link between the BDNF gene and episodic memory has been largely discussed with reference to encoding and consolidation processes (e.g., Egan et al., 2003). However, our findings thus implicate a critical role of the BDNF polymorphism also in memory retrieval. Consistent with this claim, Hariri et al. (2003) demonstrated a BDNF gene-related effect (Val/Val > Met carriers) on the magnitude of the hippocampal BOLD response during episodic retrieval. Further, given the wellestablished role of prefrontal cortex in strategic memory retrieval (e.g., Buckner, Raichle, Miezin, \& Petersen, 1996; Tulving, Markowitsch, Craik, Habib, \& Houle, 1996), and in serial recall in particular (Marshuetz, 2005), it is worth noting that Met-allele carriers of the BDNF gene have smaller frontal volumes than homozygotic Val carriers (Xu, St Clair, Ott, Feng, \& He, 2007; Pezawas et al., 2004).

Further support for the role of the BDNF polymorphism in the prefrontal cortex-medial temporal lobe circuitry comes from an analysis of errors in backward recall. These data demonstrate that older Met carriers' serial recall disadvantage was due to transposition errors rather than omissions. The higher rate of transposition errors-recalling studied items but at a wrong position-indicates that older Met carriers' performance deficit does not reflect an inability to recall an item, but rather to retrieve the correct item-item and item-position associations. This interpretation of the locus of the failure is in line with the role of BDNF in basic associative memory mechanisms (e.g., Kuczewski et al., 2009), as well as in frontally mediated retrieval operations (e.g., Xu, St Clair, et al., 2007).

Serial-recall performance as assessed here reflects the combined effects of relatively more medial temporal lobebased associative memory and frontally based working memory functions. The different portions of the serial position curve, together with the different recall directions, allowed us to differentiate among different segments of serial-order memory that rely more on associative binding (e.g., the middle and primacy portions in backward recall) and the part that relies more on working memory (e.g., the recency portion in backward recall). To further delineate the relative effects of BDNF and other memoryrelevant genes (see De Quervain \& Papassotiropoulos, 2006) on the associative and strategic aspects of episodic memory, future studies need to employ tasks that afford more precise parametric manipulations of the two aspects of memory.

In this study, we revisited the classical phenomenon of serial-order memory (Lashley, 1951; Ebbinghaus, 1885) by taking an age-comparative approach in examining the influence of the BDNF polymorphism on episodic memory. The results show that this genetic influence is most 
likely to occur under highly taxing conditions (i.e., backward serial recall of pre-recency items). Lindenberger et al. (2008) hypothesized that genetic effects on cognitive performance are most likely to be observed when brain resources are reduced. Consistent with this hypothesis, we found BDNF effects on serial recall for older, but not for younger, adults. Other evidence supporting this hypothesis was reported by Nagel et al. (2008), who found a selective impairment in executive tasks among older Met carriers of the BDNF gene who were homozygotic Val carriers of the COMT gene. Similarly, in an age-heterogeneous sample, Raz et al. $(2008,2009)$ reported a memory deficit among BDNF Met carriers with high blood pressure or high blood glucose, both being markers of vascular risk. Note that the effects of vascular risk factors on cognition and their interactions with genetic effects may depend on geographic variations in the prevalence rate of hypertension. For instance, the $60 \%$ higher prevalence of hypertension in Europe compared with the United States and Canada (Wolf-Maier et al., 2003) may result in more even distributions of genotypes across the normotensive and hypertensive subsamples, as is the case in our study, and yield different interactive patterns between individual differences in genotype and hypertension. Reduced activity-dependent up-regulation of BDNF in aging (e.g., Webster et al., 2006; Tapia-Arancibia et al., 2004) and magnified brain-volume losses among older BDNF Met carriers (Nemoto et al., 2006) are two instantiations of the general notion that age-related decline in brain resources accentuate genetic effects on cognition.

\section{Acknowledgments}

This research was supported by the Max Planck Society, including a grant from the innovation fund of the Max Planck Society (M.FE.A.BILD0002). It also was supported by a grant from the German Federal Ministry for Education and Research to the Berlin NeuroImaging Center (01GO0501). L. B. was supported by grants from the Swedish Research Council (521-2007-2892) and Swedish Brain Power, and by an Alexander von Humboldt Research Award. I. N. was supported by a predoctoral fellowship of the International Max Planck Research School, The Life Course: Evolutionary and Ontogenetic Dynamics (LIFE). We thank Kirsten Becker, Silke Becker, Karola Rockmann, Elisa Rossade, and all the other research assistants for their help. This article was revised while U. L. was a fellow at the Center for Advanced Study in the Behavioral Sciences at Stanford University.

\section{Author Contributions}

L. B., H. R. H., S. C. L., U. L., and L. N. designed research; T. v. O programmed the test battery; C. C., S. C. L., I. N., and T. v. O. supervised data collection; C. C., S. C. L., and G. P. performed the statistical analyses; T. S. performed genotyping; L. B., C. C., S. C. L., and U. L. wrote the article.

Reprint requests should be sent to Shu-Chen Li or Lars Bäckman, Center for Lifespan Psychology, Max Planck Institute for Human Development, Lentzeallee 94, D14195 Berlin, Germany, or via e-mail: shuchen@mpib-berlin.mpg.de; lars.backman.1@ki.se.

\section{REFERENCES}

Adlard, P. A., Perreau, V. M., \& Cotman, C. W. (2005). The exercise-induced expression of BDNF within the hippocampus varies across life-span. Neurobiology of Aging, 26, 511-520.

Bäckman, L., Nyberg, L., Lindenberger, U., Li, S.-C., \& Farde, L. (2006). The correlative triad among aging, dopamine, and cognition: Current status and future prospects. Neuroscience and Biobehavioral Reviews, 30, 791-807.

Berkinschtein, P., Cammarota, M., Katche, C., Slipczuk, L., Rossato, J. L., Goldin, A., et al. (2008). BDNF is essential to promote persistence of long-term memory storage. Proceedings of National Academy of Sciences, U.S.A., 105, 2711-2716.

Botvinick, M. M., \& Plaut, D. C. (2006). Short-term memory for serial order: A recurrent neural network model. Psychological Review, 113, 201-233.

Botvinick, M. M., \& Watanabe, T. (2007). From numerosity to ordinal rank: A gain-field model of serial order representation in cortical working memory. Journal of Neuroscience, 27, 8636-8642.

Brehmer, Y., Li, S.-C., Müller, V., von Oertzen, T., \& Lindenberger, U. (2007). Memory plasticity across the lifespan: Uncovering children's latent potential. Developmental Psychology, 43, 465-478.

Buckner, R. L., Raichle, M. E., Miezin, F. M., \& Petersen, S. E. (1996). Functional anatomic studies of memory retrieval for auditory words and visual pictures. Journal of Neuroscience, 16, 6219-6235.

Cabeza, R., Nyberg, L., \& Park, D. (Eds.) (2005). Cognitive neuroscience of aging. New York: Oxford University Press.

Conrad, R. (1965). Order error in immediate recall of sequences. Journal of Verbal Learning and Verbal Behavior, 4, 161-169.

Conrad, R. (1972). Short-term memory in deaf: Test for speech coding. British Journal of Psychology, 63, 173.

Dempster, E., Toulopoulou, T., McDonald, C., Bramon, E., Walshe, M., Filbery, F., et al. (2005). Association between BDNF Val(66)Met genotype and episodic memory. American Journal of Medical Genetics: Part B, Neuropsychiatric Genetics, 134B, 73-75.

De Quervain, D. J.-F., \& Papassotiropoulos, A. (2006). Identification of a genetic cluster influencing memory performance and hippocampal activity in humans. Proceedings of National Academy of Sciences, U.S.A., 103, 4270-4274.

Ebbinghaus, H. (1885). Über das Gedächtnis. Untersuchungen zur experimentellen Psychologie. Leipzig: Duncker \& Humblot.

Echeverria, D., Woods, J. S., Heyer, N. J., Rohlman, D. S., Fann, F. M., Bittner, A. C., et al. (2005). Chronic low-level mercury exposure, BDNF polymorphism, and associations with cognitive and motor function. Neurotoxicology and Teratology, 27, 781-796.

Egan, M. F., Kojima, M., Callicott, J. H., Goldberg, T. E., Kolachana, B. S., Bertolino, A., et al. (2003). The BDNF Val66Met polymorphism affects activity-dependent secretion of BDNF and human memory and hippocampal function. Cell, 112, 257-269.

Goldberg, T. E., Iudicello, J., Russo, C., Elvevåg, R., Straub, R., Egan, M. F., et al. (2008). BDNF Val ${ }^{66}$ Met polymorphism significantly affects $\mathrm{d}^{\prime}$ in verbal recognition memory at short and long delays. Biological Psychology, 77, 20-24.

Green, A. E., Munafò, M. R., DeYoung, C. G., Fossella, J. A., Fan, J., \& Gray, J. R. (2008). Using genetic data in cognitive neuroscience: From growing pains to genuine insights. Nature Reviews Neuroscience, 9, 710-720. 
Hall, J., Thomas, K. L., \& Everitt, B. J. (2000). Rapid and selective induction of BDNF expression in the hippocampus during contextual learning. Nature Neuroscience, 3, 533-535.

Hansell, N. K., James, M. R., Duffy, D. L., Birley, A. J., Luciano, M., Geffen, G. M., et al. (2007). Effect of the BDNF V166M polymorphism on working memory in healthy adolescents. Genes, Brain and Behavior, 6, 260-268.

Hariri, A. R., Goldberg, T. E., Mattay, V. S., Kolachana, B. S., Callicott, J. H., Egan, M. F., et al. (2003). Brain-derived neurotrophic factor Val66Met polymorphism affects human memory-related hippocampal activity and predicts memory performance. Journal of Neuroscience, 23, 6690-6694.

Hashimoto, R., Moriguchi, Y., Yamashita, Y., Mori, T., Nemoto, K., Okada, T., et al. (2008). Dose-dependent effect of the Val66Met polymorphism of the brain-derived neurotrophic factor gene on memory-related hippocampal activity. Neuroscience Research, 61, 360-367.

Healy, A. F. (1975). Short-term retention of temporal and spatial order. Bulletin of the Psychonomic Society, 5, 57-58.

Herlitz, A., \& Rehnman, J. (2008). Sex differences in episodic memory. Current Directions in Psychological Science, 17, 52-56.

Ho, B. C., Milev, P., O’Leary, D. S., Librant, A., Andreasen, N. C., \& Wassink, T. H. (2006). Cognitive and magnetic resonance imaging brain morphometric correlates of brain-derived neurotrophic factor Val66Met gene polymorphism in patients with schizophrenia and healthy volunteers. Archives of General Psychiatry, 63, 731-740.

Hoshi, Y., Oda, I., Wada, Y., Ito, Y., Yamashita, Y., Ohta, K., et al. (2000). Visuospatial imagery is a fruitful strategy for the digit span backward task: A study with near-infrared optical tomography. Cognitive Brain Research, 9, 339-342.

Houlihan, L. M., Harris, S. E., Luciano, M., Gow, A. J., Starr, J. M., Visscher, P. M., et al. (2009). Replication study of candidate genes for cognitive abilities: The Lothian Birth Cohort 1936. Genes, Brain and Behavior, 8, 238-247.

Kirkpatrick, E. A. (1894). An experimental study of memory. Psychological Review, 1, 602-609.

Komulainen, P., Pedersen, M., Hanninen, T., Bruunsgaard, H., Lakka, T. A., Kivipelto, M., et al. (2008). BDNF is a novel marker of cognitive function in ageing women: The DR's EXTRA Study. Neurobiology of Learning and Aging, 90, 596-603.

Kuczewski, N., Porcher, C., Lessmann, V., Medina, I., \& Gaiarsa, J. L. (2009). Activity-dependent dendritic release of BDNF and biological consequences. Molecular Neurobiology, 39, 37-49.

Lang, U. E., Hellweg, R., Seifert, F., Schubert, F., \& Gallinat, J. (2007). Correlation between serum brain-derived neurotrophic factor level and an in vivo maker of cortical integrity. Biological Psychiatry, 62, 530-535.

Lang, U. E., Sander, T., Lohoff, F. W., Hellweg, R., Bajbouj, M., Winterer, G., et al. (2007). Association of the met66 allele of brain-derived neurotrophic factor (BDNF) with smoking. Psychopharmacology, 190, 433-439.

Lashley, K. S. (1951). The problem of serial order in behavior. In L. A. Jeffress (Ed.), Cerebral mechanisms in behavior (pp. 112-131). New York: Wiley.

Lewandowsky, S., \& Murdock, B. B. J. (1989). Memory for serial order. Psychological Review, 96, 25-57.

Li, S.-C., \& Lewandowsky, S. (1993). Intralist distractors and recall direction: Constraints on models of memory for serial order. Journal of Experimental Psychology: Learning, Memory, and Cognition, 19, 895-918.

Li, S.-C., \& Lewandowsky, S. (1995). Forward and backward recall: Different retrieval processes. Journal of Experimental Psychology: Learning, Memory, and Cognition, 21, 837-847.
Li, S.-C., Lindenberger, U., \& Sikström, S. (2001). Aging cognition: From neuromodulation to representation. Trends in Cognitive Sciences, 5, 479-486.

Lindenberger, U., Nagel, I. E., Chicherio, C., Li, S.-C., Heekeeren, H. R., \& Bäckman, L. (2008). Age-related decline in brain resources modulates genetic effects on cognitive performance. Frontiers in Neuroscience, 2, 234-244.

Linnarsson, S., Bjorklund, A., \& Ernfors, P. (1997). Learning deficit in BDNF mutant mice. European Journal of Neuroscience, 9, 2581-2587.

Marshuetz, C. (2005). Order information in working memory: An integrative review of evidence from brain and behavior. Psychological Bulletin, 131, 323-339.

McClearn, G. E. (2006). Contextual genetics. Trends in Genetics, 22, 314-319.

Meyer-Lindenberg, A., \& Weinberger, D. R. (2006). Intermediate phenotypes and genetic mechanisms of psychiatric disorders. Nature Reviews Neuroscience, 7, 818-827.

Miyajima, F., Ollier, W., Mayes, A., Jackson, A., Thacker, N., Rabbitt, P., et al. (2008). Brain-derived neurotrophic factor polymorphism Vaal66Met influence cognitive ability in the elderly. Genes, Brain and Behavior, 7, 411-417.

Miyajima, F., Quinn, J. P., Horan, N., Pickles, A., Ollier, W. E., Pendleton, N., et al. (2008). Additive effect of BDNF and REST polymorphisms is associated with improved general cognitive ability. Genes, Brain and Behavior, 7, 714-719.

Monti, B., Berteotti, C., \& Contestabile, A. (2005). Dysregulation of memory-related proteins in the hippocampus of aged rats and their relation with cognitive impairment. Hippocampus, 15, 1041-1049.

Murdock, B. B. (1962). The serial position effect of free recall. Journal of Experimental Psychology, 64, 482-488.

Murdock, B. B. (1995). Developing TODAM: Three models for serial-order information. Memory \& Cognition, 23, 631-645.

Nagel, I. E., Chicherio, C., Li, S.-C., von Oertzen, T., Sander, T., Villringer, A., et al. (2008). Human aging magnifies genetic effects on executive functioning and working memory. Frontiers in Human Neuroscience, 2, 1-8.

Nemoto, K., Ohnishi, T., Mori, T., Moriguchi, Y., Hashimoto, R., Asada, T., et al. (2006). The Val66Met polymorphism of the brain-derived neurotrophic factor gene affects age-related brain morphology. Neuroscience Letters, 397, 25-29.

O'Connor, N., \& Hermelin, B. (1976). Backward and forward recall by dead and hearing children. Quarterly Journal of Experimental Psychology, 28, 83-92.

Petryshen, T. L., Sabeti, P. C., Aldinger, K. A., Fry, B., Fan, J. B., Schaffner, S. F., et al. (2009). Population genetic study of the brain-derived neurotrophic factor (BDNF) gene. Molecular Psychiatry, 1-6. (epub ahead of print 3 March 2009; doi:10.1038/mp.2009.24).

Pezawas, L., Verchinski, B. A., Mattay, V. S., Callicott, J. H., Kolachana, B. S., Straub, R. E., et al. (2004). The brain-derived neurotrophic factor Val66Met polymorphism and variation in human cortical morphology. Journal of Neuroscience, 24, 10099-10102.

Raz, N., Dahle, C. L., Rodrigue, K. M., Kennedy, K. M., Land, S. J., \& Jacobs, B. S. (2008). Brain-derived neurotrophic factor Val66Met and blood glucose: A synergistic effect on memory. Frontiers in Human Neuroscience, 2, 1-6.

Raz, N., Lindenberger, U., Rodrigue, K. M., Kennedy, K. M., Head, D., Williamson, A., et al. (2005). Regional brain changes in aging healthy adults: General trends, individual differences and modifiers. Cerebral Cortex, 15, 1676-1689.

Raz, N., Rodrigue, K. M., Kennedy, K. M., \& Land, S. (2009). Genetic and vascular modifiers of age-sensitive cognitive skills: Effects of COMT, BDNF, ApoE, and hypertension. Neuropsychology, 23, 105-116. 
Reichardt, L. F. (2006). Neurotrophin-regulated signalling pathways. Philosophical Transactions of the Royal Society of London, Series B, Biological Sciences, 361, 1545-1564.

Richardson, J. T. (2007). Measures of short-term memory: A historical review. Cortex, 43, 635-650.

Saarelainen, T., Pussinen, R., Koponen, E., Alhonen, L., Wong, G., Sirvio, J., et al. (2000). Transgenic mice overexpressing truncated trkB neurotrophin receptors in neurons have impaired long-term spatial memory but normal hippocampal LTP. Synapse, 38, 102-104.

Savitz, J., Solms, M., \& Ramesar, R. (2006). The molecular genetics of cognition: Dopamine, COMT and BDNF. Genes, Brain and Behavior, 5, 311-328.

Strauss, J., Barr, C. L., George, C. J., King, N., Shaikh, S., Devlin, B., et al. (2004). Association study of brain-derived neurotrophic factor in adults with a history of childhood onset mood disorder. American Journal of Medical Genetics Part B: Neuropsychiatric Genetics, 131B, 16-19.

Sun, X., Zhang, X., Chen, X., Zhang, P., Bao, M., Zhang, D., et al. (2005). Age-dependent brain activation during forward and backward digit recall revealed by fMRI. Neuroimage, 26, 36-47.

Talmi, D., Grady, C. L., Goshen-Gottstein, Y., \& Moscovitch, M. (2005). Neuroimaging the serial position curve: A test of single-store versus dual-store models. Psychological Science, 16, 716-723.

Tapia-Arancibia, L., Rage, F., Givalois, L., \& Arancibia, S. (2004). Physiology of BDNF: Focus on hypothalamic function.

Frontiers in Neuroendocrinology, 25, 77-107.

Thomas, J., Milner, H., \& Haberlandt, K. (2003). Forward and backward recall: Different response time patterns, same retrieval order. Psychological Science, 14, 169-174.

Tulving, E., Markowitsch, H. J., Craik, F. I. M., Habib, R., \& Houle, S. (1996). Novelty and familiarity activations in PET studies of memory encoding and retrieval. Cerebral Cortex, 6, 71-79.

Vepsäläinen, S., Castren, E., Helisalmi, S., Mannermaa, A., Lehtovirta, M., Hänninen, T., et al. (2005). Genetic analysis of BDNF and TrKB gene polymorphism in Alzheimer's disease. Journal of Neurology, 252, 423-428.

Webster, M. J., Herman, M. M., Kleinman, J. E., \& Shannon Weickert, C. (2006). BDNF and trkB mRNA expression in the hippocampus and temporal cortex during the human lifespan. Gene Expression Patterns, 6, 941-951.

Wolf-Maier, K., Cooper, R. S., Banegas, J. R., Giampaoli, S., Hense, H. W., Joffres, M., et al. (2003). Hypertension prevalence and blood pressure levels in 6 European countries, Canada, and the United States. Journal of American Medical Association, 289, 2363-2369.

World Health Organization, International Society of Hypertension Writing Group (2003). 2003 World Health Organization (WHO)/International Society of Hypertension (ISH) statement on management of hypertension. Journal of Hypertension, 21, 1981-1991.

Xu, M. Q., St Clair, D., Ott, J., Feng, G. Y., \& He, L. (2007). Brain-derived neurotrophic factor gene C-270T and Val66Met functional polymorphisms and risk of schizophrenia: A moderate-scale population-based study and meta-analysis. Schizophrenia Research, 91, 6-13. 